\title{
Adsorption Thermodynamics of Organics on Nickel- and Copper-Hexacyanoferrates
}

\author{
A. Onjia', S.K. Milonjićl', M. Todorović' , C. Loos-Neskovic ${ }^{2}$, A. Fedoroff ${ }^{3}$ and \\ D.J. Jones ${ }^{4}$ \\ 'The Vinča Institute of Nuclear Sclences, P.O. Box 522, Belgrade, Yugoslavia \\ ${ }^{2}$ Laboratorie P. Süe, C. E. N. Saclay, 91191 Gif-sur-Yvette, France \\ ${ }^{3}$ Centre d'Etudes de Chimie Métallurgique, 15 rue Georges Urbain, \\ 94407 Vitry-sur-Seine, France \\ ${ }^{4}$ Laboratorie des Agrégats Moléculaires et Matériaux inorganiques, Université \\ Montpellier II, Place Eugéne Bataillon, 34095 Montpellier, France
}

\author{
Keywords: Insoluble Hexacyanoferrates, Adsorption, Organic Molecules, Gas \\ Chromatography
}

\begin{abstract}
Adsorption of various organics on $\mathrm{Ni}$ - and $\mathrm{Cu}$-hexacyanoferrates was investigated by gassolid chromatography (inverse gas chromatography). Adsorption was studied in the temperature region from 80 to $95^{\circ} \mathrm{C}$ at zero surface coverage. Thermodynamic data of adsorption (standard free energy change, standard state enthalpies, and the entropy changes) were calculated using the surface partition coefficients. Thermodynamic parameters are discussed in terms of surface properties of used adsorbents and physicochemical properties of organic compounds.
\end{abstract}

\section{INTRODUCTION}

Heavy metal hexacyanoferrates are sparingly soluble salts and generally contain a large number of water molecules, depending on the methods of preparation and temperature of drying, but also on the types of structure of the compounds. After being dehydrated, they are able to sorb moisture from air and ammonia or other volatile solvent. Their sorption properties resemble those of zeolites, which easily and reversibly sorb water and small organic molecules. The building unit is mainly an octahedron, instead of a tetrahedron as for zeolites which have similar properties. So far, only a few data have been published on the adsorption properties of cyanometallates $[1,2]$. Effective separations of $\mathrm{C}_{6}$ isomers have been reported in [3]. Compared to classical silica-alumina molecular sieves, their advantage is a more flexible change of both geometry and dimensions of their pore system, since not only the metal ions, but also the number of vacancies and ligand can be varied [4-6].

The potentialities of gas solid chromatography (GSC) or inverse gas chromatography (IGC) for physico-chemical characterization of different solids have been known for many years [7]. IGC measurement may be carried out both at zero and finite surface coverage. In the case of zero surface coverage, vapours of testing adsorbates are injected into a column filled with solid sorbent. In this case, testing adsorbates interact with strong active sites on the examined solid surface.

Comprehensive studies on the use of IGC in the examination of adsorption from gaseous phase at infinite dilution, acid-base and some other properties of solid materials, and chemical and morphological characteristics of inorganic sorbents have been recently published [8-10].

In this study, IGC method was used to determine the thermodynamic functions for adsorption of small organic molecules on nickel- and copper-hexacyanoferrates in the Henry region. 


\section{EXPERIMENTAL}

Two hexacyanoferrates (nickel and copper), whose structures are similar but differ by the number of water molecules that can be hosted, were used as adsorbents in IGC experiments. Copper-hexacyanoferrate was obtained by precipitation method [11], while nickel-hexacyanoferrate was obtained using a local growth method of preparation [12]. Chemical compositions of the products used for adsorption experiments are: $\mathrm{Cu}_{1.97} \mathrm{Fe}(\mathrm{CN})_{6} \cdot 8.7 \mathrm{H}_{2} \mathrm{O}$ (designated as $\left.\mathrm{Cu}_{2}{ }_{2} \mathrm{Fe}^{\mathrm{II}}(\mathrm{CN})_{6}\right)$ and $\mathrm{Na}_{1.83} \mathrm{Ni}_{0.93} \mathrm{Fe}(\mathrm{CN})_{6} .2 .6 \mathrm{H}_{2} \mathrm{O}$ (designated as $\mathrm{Na}_{2} \mathrm{NiFe}^{\mathrm{II}}(\mathrm{CN})_{6}$ ). The obtained material was ground and sieved. The fractions of $0.16-0.20 \mathrm{~mm}$ were used as gas chromatography column packing.

The specific surface areas of the obtained metalhexacyanoferrates were determined by the BET method from low-temperature nitrogen adsorption isotherms. The values found for $\mathrm{Cu}_{2}{ }_{2} \mathrm{Fe}^{\mathrm{II}}(\mathrm{CN})_{6}$ and $\mathrm{Na}_{2} \mathrm{NiFe}^{\mathrm{II}}(\mathrm{CN})_{6}$ are 972 and $48 \mathrm{~m}^{2} \mathrm{~g}^{-1}$, respectively.

The chromatographic experiments were performed by a Spectra Physics Model 7100 research gas chromatograph equipped with a flame ionization detector. Dry nitrogen was used as a carrier gas with a flow rate of about $32 \mathrm{~cm}^{3} \mathrm{~min}^{-1}$. The column inlet pressure was measured by a precision manometer and the outlet pressure, assumed to be atmospheric, by a precision barometer. The stainless steel columns $(50 \mathrm{~cm}$ long and $2.2 \mathrm{~m}$ in diameter) were cleaned with both polar $\left(\mathrm{C}_{2} \mathrm{H}_{5} \mathrm{OH}\right)$ and nonpolar $\left(\mathrm{C}_{6} \mathrm{H}_{14}\right)$ solvents prior to packing. After the packing, each column was conditioned overnight in a stream of nitrogen (flow rate $5 \mathrm{~cm}^{3} \mathrm{~min}^{-1}$ ) at $388 \mathrm{~K}$. Chemical analysis of the adsorbents, made after IGC experiments, revealed the following compositions: $\mathrm{Cu}_{1.87} \mathrm{Fe}(\mathrm{CN})_{6} \cdot 1.1 \mathrm{H}_{2} \mathrm{O}$ and $\mathrm{Na}_{1.94} \mathrm{Ni}_{0.89} \mathrm{Fe}(\mathrm{CN})_{6} \cdot 2.6 \mathrm{H}_{2} \mathrm{O}$. The obtained results confirm that the chemical composition of nickel-hexacyanoferrate was not modified by heating at $388 \mathrm{~K}$. In the case of copper-hexacyanoferrate, heating at the same temperature leads to a drastic loss of water molecules. The amounts of $\mathrm{Cu}_{2}{ }_{2} \mathrm{Fe}^{\mathrm{II}}(\mathrm{CN})_{6}$ and $\mathrm{Na}_{2} \mathrm{NiFe}^{\mathrm{ll}}(\mathrm{CN})_{6}$ in the columns, measured after IGC experiments, were $1.2942 \mathrm{~g}$ and $1.0551 \mathrm{~g}$, respectively. The organic adsorbates (n-hexane, cyclohexane, chloroform and benzene), obtained from various commercial sources, were of analytical grade and injected, as the smallest detectable amount of vapour, into the chromatograph using a $1 \mu \mathrm{l}$ Hamilton microsyringe. Each adsorbate was injected at least 3 times and retention times were averaged. These mean retention times were used in further calculations of net retention volumes. The system dead-time was assumed to be equal to the retention time of methane at the column temperature. The range of experimental temperatures was $80-95^{\circ} \mathrm{C}$, and under these conditions all chromatographic peaks were symmetrical and the retention times did not depend on the amount injected, indicating that Henry's law region was attained.

The adsorbate net retention volumes, $\mathrm{V}_{\mathrm{N}}$, were calculated from the expression

$$
V_{N}=\left(t_{R}-t_{o}\right) \cdot F_{f} \cdot \frac{T}{T_{f}}\left(\frac{p_{o}-p_{w}}{p_{o}}\right) j
$$

where $t_{R}$ is the adsorbate retention time, $t_{0}$ is the retention time of an unretained compound (in our case methane), $\mathrm{F}_{\mathrm{f}}$ is the flow rate measured with a soap bubble flowmeter at temperature $T_{\mathrm{f}}, \mathrm{T}$ is the column temperature, $p_{o}$ is the column outlet pressure (taken as barometric), $p_{w}$ is the vapour pressure of water at $T_{f}$, and $j$ is the James-Martin gas compressibility correction factor. The surface partition coefficient, $K_{s}$, defined as the net retention volume per unit of the adsorbent surface area $\left(A_{s}\right)$, was then calculated as

$$
K_{s}=\frac{V_{N}}{A_{s}}
$$

where $A_{S}$ is the product of the specific surface area, $S$, and the mass of metal-hexacyanoferrate in the column, $\mathrm{m}$. 


\section{RESULTS AND DISCUSSION}

Table 1 presents the surface partition coefficients of investigated adsorbates for all temperatures and two hexacyanoferrates. As expected, the surface partition coefficients of the adsorbates decrease with increase in column temperature. Although cyclohexane boils at a temperature $12 \mathrm{~K}$ higher than hexane its retentions are shorter. Explanation for such a behaviour can be easily found in geometric properties of the molecules under consideration. In the case of hexane, all the six carbon atoms can approach a plane, while for cyclohexane only three or four of them can interact with a surface at the same time, depending on the steric form that cyclohexane may take. The aromatics interact with the adsorbent surface by $\pi$-electrons [7] and, consequently, the interaction of benzene with the hexacyanoferrates surface is much stronger than that of $n$-hexane or cyclohexane (Table 1).

Table 1. Partition coefficients, $\mathrm{K}_{\mathrm{s}}\left(\mathrm{cm}^{3} \mathrm{~m}^{-2}\right)$, for test adsorbates on a) nickelhexacyanoferrate and b) copper-hexacyanoferrate at indicated temperatures.

\begin{tabular}{|c|c|c|c|c|c|}
\hline & \multicolumn{5}{|c|}{ Column temperature, $\mathrm{K}$} \\
\hline Adsorbate & B.p.(K) & 353 & 358 & 363 & 368 \\
\hline \multicolumn{6}{|l|}{ a) } \\
\hline n-hexane & 342.2 & 0.162 & 0.121 & 0.092 & 0.074 \\
\hline Cyclohexane & 354.6 & 0.054 & 0.042 & 0.037 & 0.031 \\
\hline Chloroform & 334.5 & 0.084 & 0.066 & 0.055 & 0.050 \\
\hline Benzene & 353.3 & 0.233 & 0.187 & 0.153 & 0.123 \\
\hline \multicolumn{6}{|l|}{ b) } \\
\hline n-hexane & 342.2 & 0.032 & 0.025 & 0.020 & 0.016 \\
\hline Cyclohexane & 354.6 & 0.036 & 0.029 & 0.023 & 0.019 \\
\hline Chloroform & 334.5 & 0.032 & 0.025 & 0.021 & 0.016 \\
\hline Benzene & 353.3 & 0.128 & 0.097 & 0.073 & 0.057 \\
\hline
\end{tabular}

The thermodynamic data describing the adsorption process can be derived from the partition coefficients and their temperature dependence. The standard free energy change of adsorption, $\Delta \mathrm{G}_{\mathrm{a}}{ }^{\circ}$, was calculated from the relation $[13,14]$

$$
\Delta \mathrm{G}_{\mathrm{a}}{ }^{\mathrm{o}}=-\mathrm{RT} \ln \left(\mathrm{K}_{\mathrm{s}} \mathrm{p}_{\mathrm{s}, \mathrm{g}} / \Pi_{\mathrm{s}}\right)
$$

or

$$
\Delta \mathrm{G}_{\mathrm{a}}{ }^{\mathrm{o}}=-\mathrm{RT} \ln \mathrm{V}_{\mathrm{N}}+\mathrm{C}
$$

where $\mathrm{R}$ is the gas constant, $\mathrm{T}$ is the column temperature, $\mathrm{p}_{\mathrm{s}, \mathrm{g}}$ is the adsorbate standard state vapour pressure, and $\Pi_{s}$ is the two-dimensional standard-state (surface) spreading pressure of the adsorbed gas. The standard reference state is taken [13-15] as $\mathrm{p}_{\mathrm{s}, \mathrm{g}}=101 \mathrm{kNm}^{-2}(101 \mathrm{kPa})$ and $\Pi_{\mathrm{s}}=0.338 \mathrm{mNm}^{-1}$. Constant $\mathrm{C}$ takes into account the mass and specific surface area of adsorbent in the column and the standard states of the adsorbates in the mobile and adsorbed states [16].

The data for the standard free energy change of adsorption at $353 \mathrm{~K}$ are given in Table 2 . All that was said for the $K_{s}$ values also holds for the $\Delta G_{a}{ }^{\circ}$ values, since the two properties are proportional (cf. Eq. 3). The role of the specific part of interaction can be evaluated considering the differential standard free energy of adsorption $\Delta\left(\Delta \mathrm{G}_{\mathrm{a}}{ }^{\circ}\right)$. For a pair $\mathrm{n}$-hexane-benzene, $\Delta\left(\Delta G_{a}^{o}\right)=\Delta G_{C_{b} H_{6}}^{o}-\Delta G_{n C_{6}}^{o}$. The values of $\Delta\left(\Delta \mathrm{G}_{\mathrm{a}}{ }^{\circ}\right)$ for a pair of adsorbates, benzene and $\mathrm{n}$-hexane at $353 \mathrm{~K}$, on nickel- and copper-hexacyanoferrates are -1.08 and -4.09 , respectively. 
Table 2 Standard free energy change, $\Delta \mathrm{G}_{\mathrm{a}}{ }^{\circ}$, at $353 \mathrm{~K}$ for listed adsorbates on nickelhexacyanoferrate and copper-hexacyanoferrate.

\begin{tabular}{|lcc|}
\hline & \multicolumn{3}{|c|}{$-\Delta \mathrm{G}_{\mathrm{a}}{ }^{\circ}\left(\mathrm{kJ} \mathrm{mol}^{-1}\right)$} \\
\hline Adsorbate & $\mathrm{Na}_{2} \mathrm{NiFe}^{\mathrm{II}}(\mathrm{CN})_{6}$ & $\mathrm{Cu}_{2}{ }_{2}^{\mathrm{II}} \mathrm{Fe}^{\mathrm{II}}(\mathrm{CN})_{6}$ \\
\hline n-hexane & 11.38 & 6.60 \\
\hline Cyclohexane & 8.15 & 7.00 \\
\hline Chloroform & 9.45 & 6.60 \\
\hline Benzene & 12.46 & 10.69 \\
\hline
\end{tabular}

The differential heats of adsorption of the adsorbates, $\mathrm{q}_{\mathrm{d}}$, at zero coverage, i.e., the standardstate enthalpies of adsorption, $\Delta \mathrm{H}_{d}{ }^{\circ}$, were obtained from the temperature dependence of $\mathrm{K}_{\mathrm{s}}$, viz.

$$
\mathrm{d}\left(\ln \mathrm{K}_{\mathrm{s}}\right) / \mathrm{d}(1 / \mathrm{T})=-\Delta \mathrm{H}_{\mathrm{d}}{ }^{\circ} / \mathrm{R}
$$

The relation between the differential heat of adsorption and the isosteric heat of adsorption, $\mathrm{q}_{\mathrm{st}}$, is given by

$$
\mathrm{q}_{\mathrm{st}}=\mathrm{q}_{\mathrm{d}}+\mathrm{RT}
$$

The isosteric heat of adsorption, $\mathrm{q}_{\mathrm{st}}$ (or the isosteric enthalpy of adsorption, $-\Delta \mathrm{H}_{\mathrm{st}}$ ) at zero coverage is obtained from a plot of $\ln \left(\mathrm{K}_{\mathrm{s}} / \mathrm{T}\right)$ against $1 / \mathrm{T}$.

Plots of $\ln _{5}$ vs $1 / T$ of the used compounds with nickel- and copper-hexacyanoferrates are shown in Fig. 1. The values of $\Delta \mathbf{H}_{\mathrm{d}}{ }^{\mathrm{d}}$, calculated from the least-squares determination of the corresponding slopes, according to Eq. (4), are compiled in Table 3.

In the table, the heats of liquefaction, $\Delta \mathrm{H}_{\mathrm{L}}$, for investigated adsorbates (taken from reference [17]) are also presented for comparison. The more negative the $\Delta \mathrm{H}_{\mathrm{d}}{ }^{\circ}$ value, the greater the interaction between the adsorbate and adsorbent. It is evident from the data that benzene exhibits more negative $\Delta \mathrm{H}_{\mathrm{d}}{ }^{\mathrm{O}}$ than the corresponding values for aliphatic and alicyclic hydrocarbons with the same carbon number (i.e., hexane and cyclohexane). The more negative the heat, the stronger the interaction between the adsorbate and the adsorbent. Adsorption enthalpies for all adsorbates are greater than the corresponding enthalpies of liquefaction, $-\Delta H_{l}$.

Table $3 \mathrm{H}_{\mathrm{d}}{ }^{0}\left(\mathrm{~kJ} \mathrm{~mol}^{-1}\right)$ and $\Delta \mathrm{H}_{\mathrm{L}}\left(\mathrm{kJ} \mathrm{mol}^{-1}\right)$ values for listed adsorbates with nickelhexacyanoferrate and copper-hexacyanoferrate.

\begin{tabular}{|lccc|}
\hline \multicolumn{4}{|c|}{$-\Delta \mathrm{H}_{\mathrm{d}}{ }^{\mathrm{O}}$} \\
\hline Adsorbate & $\mathrm{Na}_{2} \mathrm{NiFe}^{\mathrm{II}}(\mathrm{CN})_{6}$ & $\mathrm{Cu}_{2}{ }_{2} \mathrm{Fe}^{\mathrm{II}}(\mathrm{CN})_{6}$ & $-\Delta \mathrm{H}_{\mathrm{L}}$ \\
\hline n-hexane & 39.6 & 47.6 & 31.9 \\
cyclohexane & 39.0 & 48.1 & 32.8 \\
\hline chloroform & 38.1 & 48.5 & 31.4 \\
\hline benzene & 45.5 & 57.9 & 34.1 \\
\hline
\end{tabular}

The corresponding standard-state entropy changes of adsorption, $\Delta \mathrm{S}_{\mathrm{a}}{ }^{\mathrm{o}}$, were calculated from

$$
\Delta \mathrm{S}_{\mathbf{a}}{ }^{\mathrm{o}}=\left(\Delta \mathrm{H}_{\mathbf{d}}{ }^{0}-\Delta \mathrm{G}_{\mathbf{a}}{ }^{0}\right) / \mathrm{T}
$$

The entropy changes for adsorption of the investigated adsorbates could be calculated according to de Boer [18]. The three-dimensional translation entropy of the adsorbate as an ideal gas is given by

$$
{ }_{3} \mathrm{~S}_{\mathrm{t}}=\mathrm{R} \ln \left(\mathrm{M}^{3 / 2} \mathrm{~T}^{5 / 2}\right)-9.62
$$

where $M$ is the molar mass of adsorbate and the entropy ${ }_{3} S_{t}$ is expressed in $\mathrm{Jmol}^{-1} \mathrm{~K}^{-1}$. Similarly, the entropy of the adsorbate as an ideal, mobile, two-dimensional gas (having unrestricted freedom of 
movement in two directions only but not in the direction perpendicular to the surface), may be calculated from

$$
{ }_{2} S_{\mathrm{t}}=\mathrm{R} \ln (\mathrm{MTA})+275.31
$$

where $\mathrm{A}$ is the area, in the standard state, available for a molecule. Using the standard state of de Boer [18], $\mathrm{A}$ is $4.08 \mathrm{~T} 10^{-16} \mathrm{~cm}^{2}$.

The calculated values for ${ }_{3} S_{t},{ }_{2} S_{t}$, and the predicted entropy changes, $\Delta S_{t},\left(\Delta S_{t}={ }_{2} S_{t}-{ }_{3} S_{t}\right)$ for adsorption of the studied adsorbates are shown in Table 4. For comparison, the experimental values of $\Delta \mathrm{S}_{\mathrm{a}}{ }^{0}$ obtained by means of Eq. (6) are also given in Table 4.
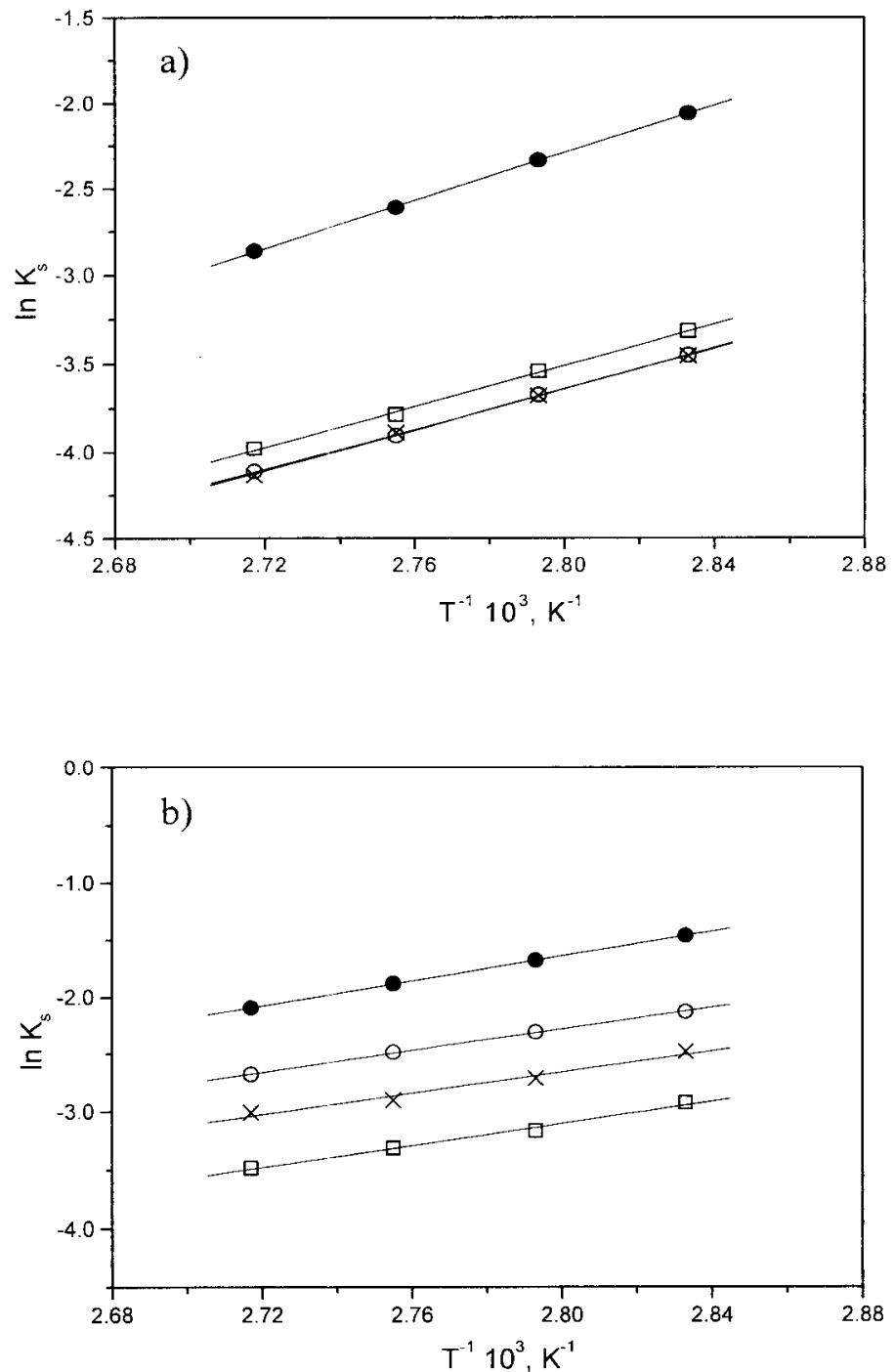

Figure 1. Plots of $\operatorname{lnK}_{\mathrm{s}}$ vs. $1 / \mathrm{T}$ for the adsorbates on copper-hexacyanoferrate (a) and nickelhexacyanoferrate (b). o n-hexane, $\sqcup$ cyclohexane, x chloroform, • benzene. 
Table 4 Values of entropies and entropy changes of investigated adsorbates at $353 \mathrm{~K}$. All values are in $\mathrm{Jmol}^{-1} \mathrm{~K}^{-1}$.

\begin{tabular}{|lccccc|}
\hline \multicolumn{7}{c|}{$-\Delta \mathrm{S}_{\mathrm{a}}{ }^{0}$} \\
\hline Adsorbate & ${ }_{3} \mathrm{~S}_{\mathrm{t}}$ & ${ }_{2} \mathrm{~S}_{\mathrm{t}}$ & $-\Delta \mathrm{S}_{\mathrm{t}}$ & Ni-hex. & Cu-hex. \\
\hline n-hexane & 167.9 & 115.3 & 52.6 & 102.7 & 116.3 \\
\hline cyclohexane & 167.6 & 115.1 & 52.5 & 113.3 & 116.5 \\
\hline chloroform & 172.0 & 118.0 & 54.0 & 109.7 & 117.8 \\
\hline benzene & 166.7 & 114.5 & 52.2 & 128.6 & 133.6 \\
\hline
\end{tabular}

Differences observed between the experimental and the predicted entropy changes, i.e., additional entropy loss found experimentally, may result from a restricted rotational and vibrational freedom of the adsorbates on the investigated metal hexacyanoferrates surfaces.

\section{Acknowledgements}

This research was supported in part by the Ministry of Sciences, Belgrade, Serbia, and French-Yugoslav Project No. 9607.

\section{REFERENCES}

[1] G.B. Seifer, Zh. Neorg. Khim., 4, 841 (1959).

[2] G.B. Seifer, Zh. Neorg. Khim., 7, 899 (1962).

[3] G. Boxhoorn, J. Moolhuysen, J.G.F. Csolegem, A. Van Santen, J. Chem. Soc., Chem. Commun., 1305 (1985).

[4] W.O. Milligan, M. Uda, M.L. Beasley, D.R. Dillin, W.E. Bailey, J.J. McCoy, U.S. Office of Saline Water, Res.Dev. Prog. Report, OSW-PR-594 (1970).

[5] D.F. Mullica, D.B. Tippin, E.L. Sappenfied, J.Coord.Chem., 24, 83 (1991).

[6] D.F. Mullica, W.O. Milligan, G.W. Beall, W.L. Reeves, Acta Cryst., B34, 3558 (1978).

[7] A.V. Kiselev, Ya.I. Yashin, "Gazo-Adsorbtsionnaya Khromatografiya" (Gas-Adsorption Chromatography), Nauka, Moscow (1967).

[8] F.J. Lopez Garzon, M. Domingo Garcia, in A. Dabrowski and V.A. Tertykh (Eds.), "Adsorption on New and Modified Inorganic Sorbents", Studies in Surface Science and Catalysis, vol. 99, pp. 517-537, Elsevier, Amsterdam (1996).

[9] A. Voelkel, in A. Dabrowski and V.A. Tertykh (Eds.), "Adsorption on New and Modified Inorganic Sorbents", Studies in Surface Science and Catalysis, vol. 99, pp. 465-477, Elsevier, Amsterdam (1996).

[10]E. Papirer, H. Balard, in A. Dabrowski and V.A. Tertykh (Eds.), "Adsorption on New and Modified Inorganic Sorbents", Studies in Surface Science and Catalysis, vol. 99, pp. 478-502, Elsevier, Amsterdam (1996).

[11]S. Ayrault, C. Loos-Neskovic, M. Fedoroff, E. Garnier, D.J. Jones, Progress in Ion Exchange, The Royal Society of Chemistry Spec. Publ. n 196, Cambridge (1997), p. 279.

[12] C.Loos-Neskovic, S. Abousahl, M. Fedoroff, J. Mater. Sci., 25, 677 (1990).

[13] S. Katz, D.G. Gray, J. Colloid Interface Sci., 82, 318 (1981).

[14] S.K. Milonjić, M.M. Kopečni, Chromatographia, 19, 342 (1984).

[15]J.H. de Boer, "The Dynamical Character of Adsorption", p. 49, Clarendon, Oxford (1953).

[16]E.F. Meyer, J. Chem. Ed., 57, 120 (1980).

[17] Handbook of Chemistry and Phisics (Ed.R.C. Weast), $69^{\text {th }}$ Edition, CRC Press, Boca Raton, Fl, USA, 1988, pp. C672-680.

[18]J.H. de Boer, "The Dynamical Character of Adsorption", pp. 112-115, Clarendon, Oxford (1953). 
Advanced Materials and Processes: YUCOMAT '97

10.4028/www.scientific.net/MSF.282-283

Adsorption Thermodynamics of Organics on Nickel- and Copper-Hexacyanoferrates 10.4028/www.scientific.net/MSF.282-283.183

\section{DOI References}

[5] D.F. Mullica, D.B. Tippin, E.L. Sappenfied, J.Coord.Chem., 24, 83 (1991).

doi:10.1080/00958979109409738

[6] D.F. Mullica, W.O. Milligan, G.W. Beall, W.L. Reeves, Acta Cryst., B34, 3558 (1978).

doi:10.1107/S0567740878011589

[13] S. Katz, D.G. Gray, J. Colloid Interface Sci., 82, 318 (1981).

doi:10.1016/0021-9797(81)90374-X 